Acta Crystallographica Section A

Foundations of Crystallography

ISSN 0108-7673

\section{Ewald Prize awarded to Professor Michael Woolfson}

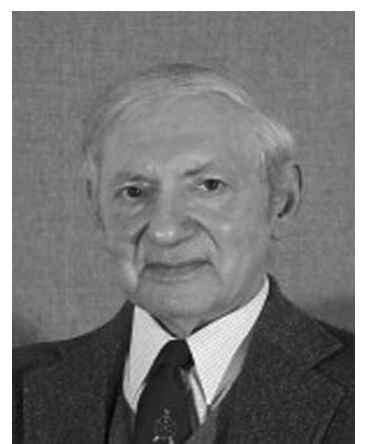

The IUCr is pleased to announce that Professor Michael M. Woolfson has been awarded the sixth Ewald Prize for his exceptional contributions in developing the conceptual and theoretical framework of direct methods along with the algorithm design and computer programs for automatic solutions that changed the face of structural science and for his contributions to crystallographic education and international collaboration, which have strengthened the intellectual development of crystallographers worldwide.

The presentation of the Ewald Prize will be made during the Geneva Congress Opening Ceremony on 6 August 2002. 